\title{
O Deficit Orçamentário e a Política Financeira
}

\author{
Sebastião de Sant'Anna E Sillva
}

$\mathrm{N}$

o campo da política financeira o deficit orçamentário é talvez o problema em tôrno do qual é mais intensa a controvérsia e mais ampla a divergência.

O próprio conceito de equilíbrio orçamentário é impreciso e flutuante, não propiciando um fundamento sólido para servir de base às discussões teóricas. Em princípio o orçamento estará equilibrado se houver igualdade aritmética entre a coluna das receitas, de um lado, e a coluna das despesas, de outro. Essa igualdade poderá existir "ex-ante", ou seja por ocasião da estimativa das receitas e despesas. Todavia, após a execução do orçamento, sòmente por acaso será possível a identidade entre a receita arrecadada e a despesa realizada. Para a política financeira o mais importante é porém o resultado final do exercício, a saber o balanço das contas orçamentárias, quando as freqüentes manipulações nas estimativas não se tornam mais possíveis ou, pelo menos, são mais difíceis e podem fàcilmente ser descobertas. Nessas condições, considera-se na prática como equilibrado o orçamento cuja execução se encerra com o superavit correspondente ao excesso da receita arrecadada sôbre a despesa efetuada. Será deficitário o orçamento quando as receitas auferidas pelo Tesouro não tenham sido suficientes para cobrir as despesas a seu cargo.

A imprecisão continua, quando se procura definir o que é receita e o que é despesa. Em um sentido amplo, receita é o total de meios de pagamento à disposição do Tesouro a qualquer título e, dentro dêsse conceito, - produto dos empréstimos e depósitos e as próprias emissões de papel moeda de curso forçado seriam consideradas receitas. Nesse caso nunca verificar-se-ia um deficit orçamentário, pois é evidente que, para realizar um certo volume de despesas, dispôs o Tesouro dos meios de pagamento correspondentes, obtidos dos particulares mediante transferência corıpulsória ou voluntária, venda de bens e serviços ou criados pelo Estado mediante uso da faculdade emissora. Costuma-se portanto restringir o conceito de receita pública apenas ao total de meios de pagamento captados pelo Tesouro a título definitivo, mediante transferência, também definitiva, de poder de compra dos particulares, indeperdentes da obrigação da restituição no futuro das importâncias arrecadadas. Em linguagem mais técnica será portanto receita ùnicamente a transferência compulsória e definitiva para o setor público de uma parte da renda produzida pelo setor privado da economia. Esse conceito exclui da receita pública o produto de empréstimos 
voluntários ou compulsórios e dos depósitos, a emissão de papel moeda de curso forçado, os preços cobrados pela venda de serviços ou mercadorias produzidos pelas emprêsas industriais e comerciais do Estado bem como a alienação de bens públicos.

De outro lado, a despesa pública pode ter também um sentido amplo e um sentido restrito. Em sentido amplo a despesa pública abrangerá a totalidade dos pagamentos feitos pelo Tesouro a qualquer título, inclusive amortização de empréstimos contraídos, restituição de depósitos e resgate de papel moeda. Compreenderá, também, os investimentos feitos em bens de capital, quando ao dispêndio de numerário corresponde um aumento equivalente do ativo do Estado ou do patrimônio público. Em sentido restrito constituirá porém despesa pública apenas a compra, pelo Estado, dos serviços e mercadorias necessários à manutenção e funcionamento dos serviços públicos não industriais bem como à realização de transferências definitivas de rendas do setor público para o setor privado da economia.

Segundo essa linha de raciocínio, para apurar com exatidão a existência de um deficit ou superavit nas contas públicas deveremos desdobrar o orçamento do Estado em três grandes divisões.

A primeira divisão corresponderá ao denominado orçamento corrente ou de custeio, contendo, de um lado, as receitas tributárias e as decorrentes do poder punitiva: impostos, taxas, contribuições, multas e penas pecuniárias, que representam transferências compulsórias e definitivas, para o Tesouro, de rendas do setor privado da economia, bem como o lucro das emprêsas industriais ou comerciais do Estado. Do outro lado serão incluídos os gastos correntes, correspondentes ao consumo, pelo Estado, de mercadorias e serviços necessários à manutenção e funcionamento dos serviços não industriais, bem como as despesas representando transferências de rendas do setor público para o setor privado, inclusive pagamento dos juros da dívida pública e cobertura do deficit de operação das emprêsas públicas de natureza industrial ou comercial.

A segunda divisão será constituída pelas operações financeiras do Estado na qualidade de empresário ou seja como proprietário de emprêsas industriais e comerciais. Na coluna da receita incluir-se-á o produto da venda das mercadorias e serviços produzidos pelas emprêsas públicas e na coluna das despesas o total dos gastos de operação com a sua manutenção e funcionamento. Se do cotejo entre as duas colunas resultar um saldo positivo, correspondente ao lucro verificado na exploração dessas-emprêsas, será o mesmo incorporado à receita do orçamento corrente. Se, pelo contrário, a exploração das emprêsas ocasionar um deficit coberto pelo Tesouro, a cobertura dêsse deficit constituiria uma transferência, consignada. como despesa do orçamento corrente.

A terceira divisão constituirá o denominado orçamento de capital, em que se incluirão os dispêndios de numerário efetuados pelo Tesouro na execução de investimentos governamentais, ou seja a participação do Estado na formação do capital nacional, inclusive subscrição de ações de emprêsas públicas ou sociedades de economia mista, bem como amortização de emprés timòs públicos contraídos para o financiamento dêsses investimentos. Do lado da receita incluir-se-á o produto dos empréstimos de caráter voluntário 
ou compulsório destinados ao financiamento dos investimentos governamentais e o saldo porventura apurado no orçamento corrente.

Feita essa tríplice divisão o problema da existência de deficit ou superavit nas contas públicas torna-se mais claro e suscetível de conceituação muito mais precisa. De outro lado, os efeitos para a economia do país do resultado das contas públicas podem ser apreciados com maior precisão.

O orçamento corrente ou de custeio abrange os gastos efetuados com a manutenção e funcionamento de serviços ligados às finalidades básicas do Estado: defesa, justiça, segurança, educação, assistência etc. Tratando-se de serviços prestados indistintamente a tôda população o seu custc não é divisível pelos beneficiários nem se torna possível cobrar de cada un o preço equivalente ao valor do benefício recebido. Além disso corresponciem tais gastos a um consumo definitivo, pelo Estado, de mercadorias e serviços necessários à execução das atividades governamentais. Não há assim outra forma de financiá-los a não ser por meio de impostos, contribuições de catáter geral, nas quais não há equivalência entre a importância paga pelo contribuinte e o benefício a êle prestado pelo Estado. Determinam também os impostos transferências definitivas de rendas do setor privado para o setor público, circunstância que os torna adequados para financiamento de gastos de consumo como o são as despesas correntes do Govêrno.

Um orçamento corrente deficitário significa estar o Govêrno consumindo uma quantidade de mercadorias e serviços maior do que as rendas transferidas do setor privado para o setor público através da tributação. Essa diferença terá de ser coberta através de empréstimos ou da criação de novos meios de pagamento. Se é usada a primeira solução, o empréstimo realiza um processo de descapitalização, ao transferir poupança destinada a investimentos privados a fim de aplicá-la em despesas de consumo. Se novos meios de pagamento são criados para cobertura dêsse deficit, o efeito é equivalente ao da cobrança de um impôsto geral, iníquo e indiscriminado, sôbre tôdas as mercadorias e serviços, cuja alta de preços provoca.

O orçamento corrente, quando rigorosamente equilibrado, é um instrumento neutro, pois não afeta o equilíbrio econômico preexistente. Transfere o Estado em seu benefício rendas do setor privado, utilizando-as no consumo de mercadorias e serviços. Comprime portanto o consumo do setor privado a fim de possibilitar consumo equivalente do setor público. Um orçamento corrente deficitário significa uma expansão excessiva do consumo do setor público não compensada por compressão idêntica no setor privado. O desequilíbrio sòmente será restabelecido à custa de uma utilização de parte da poupança privada em despesas de consumo (empréstimo) ou mediante elevação geral do nível de preços (inflação monetária). Um superavit do orçamento corrente significa que o Estado está comprimindo o consumo privado através da tributação e poupando uma parcela da renda transferida para o setor público.

As chamadas despesas de transferência: subvenções, auxílios, juros da dívida pública, proventos de inatividade, pensões etc. não devem afetar o equilíbrio do orçamento corrente. Significam tão sòmente a transferência, pelo Estado, de rendimentos produzidos pelo setor privado a fim de entregálos a certos grupos, classes ou indivíduos. Os rendimentos assim transferidos 
não se destinam ao custeio de serviços produzidos e prestados pelo Govêrno mas a possibilitar um processo de redistribuiçção compulsória de renda julgada conveniente por motivos de ordem social ou política.

Se o gasto total com a exploração das emprêsas públicas é integralmente ccberto pela venda dos serviços e mercadorias, isto é, se tais emprêsas são auto-suficientes, a atividade industrial do Estado é neutra, sob o aspecto financeiro. Se essa exploração é deficitária, o saldo negativo irá pesar sôbre c orçamento de custeio, representando um gasto de transferência coberto através dos impostos. Em última análise, pagarão os contribuintes impostos para que os serviços e mercadorias produzidos pelas emprêsas governamentais possam ser vendidos por preço inferior ao custo de produção. Se, ao contrário, tais emprêsas proporcionam um saldo positivo, ou seja um lucro de operação, o saldo assim obtido e incorponado à receita do orçamento corrente diminuirá ônus fiscal sôbre a coletividade.

Finalmente, no tocante aos investimentos governamentais, o problema do respectivo financiamento é inteiramente diverso. É a parcela da renda nacional não consumida e portanto poupada que proporciona os recursos para o financiamento dos investimentos essenciais a qualquer coletividade. Uma parte da poupança global deverá financiar os investimentos privados e outra parte os investimentos públicos. As despesas de capital a cargo do Govêrno deverão ser financiadas por uma parte da poupança global, para êsse fim transferida do setor privado para o setor público da economia. O empréstimo público, compulsório ou voluntário, constitui o instrumento normal utilizado pelo Estado para transferir poupança privada para o Tesouro. Assim sendo é de se considerar equilibrado o orçamento de capital se a totalidade das despesas correspondentes a investimentos tiver o seu financiamento garant:do por. meio de empréstimos compulsórios ou voluntários feitos pelo público ao Govêrno. Um orçamento de capital dêsse tipo é neutro, visto não afetar o volume de poupança global nem o total dos investimentos.

Se o orçamento corrente apresenta um superavit e êsse é transferido para a receita do orçamento de capital a fim de contribuir para o financiamento do programa de investimentos, isso significa que o Estado está comprimindo o consumo através da tributação a fim de aumentar a poupança global e possibilitar maior volume de investimentos.

Resumindo as considerações anteriores poderemos afirmar :

a) O orçamento corrente está equilibrado quando as receitas provenientes da tributação são suficientes para atender às despesas com a manutenção e funcionamento dos serviços públicos não industriais, bem como às despesas de transferência e os gastos com a cobertura do deficit de exploração das emprêsas industriais do Estado;

b) $\mathrm{O}$ orçamento corrente está desequilibrado se as receitas tributárias não são suficientes para atender às despesas mencionadas no item anterior e para a respectiva cobertura o Estado lança mão de empréstimos ou da emissão de papel moeda de curso forçado;

c) O equilíbrio financeiro não é afetado se as emprêsas industriais e. comerciais do Estado são auto-suficientes em seu conjunto ou se o deficit de exploração nelas verificado é coberto integralmenta por meio de impostos; 
d) O orçamento de capital estará equilibrado se as despesas com investimentos foram cobertas pelo produto de empréstimos públicos, exclusivamente, ou então com êsse produto e mais o saldo, se houver, do orçamento corrente;

e) O cıçamento de capital estará desequilibrado se, para o seu financiamento total ou parcial, criar o Estado meios de pagamento.

Os economistas e financistas da escola clássica condenavam, por princípio e em quaisquer circunstâncias, o desequilíbrio orçamentário. Êsse ponto de vista será perfeitamente compreensível se tivermos em conta que, para os clássicos, o orçamento público bem como a política fiscal em seu conjunto deveriam ser neutros isto é não podiam afetar o equilíbrio econômico que, conforme pensavam, se realizava automàticamente pelo livre jôgo das leis da oferta e da procura. Para que essa neutralidade do orçamento do Estado fôsse conseguida considerava-se necessár:o, em primeiro lugar, que as despesas públicas de custe:o bem como os investimentos governamentais fôssem limitados ao mínimo essencial, permitindo assim ao setor privado da economia o máximo de expansão. Em segundo lugar, o orçamento, tanto o corrente quanto o de capital, deveria ser sempre mantido em rigoroso equilíbrio, pois assim evitar-se-iam os indesejáveis reflexc's do desequilíbrio das contas públicas sôbre o sistema monetário e sôbre a estabilidade dos preços.

A grande depressão econômica entre os dois conflitos mundiais dêste século, ao desmentir a alegada e permanente tendência do regime de produção capitalista para o equilíbrio econômico e pleno emprêgo dos fatôres de produção, demonstrou a possibilidade da utilização da política orçamentária e fiscal para a correção dos desequilíbrios cíclicos. Umá vez verificado que a depressão e o desemprêgo resultavam de uma deficiência da procura global para a absorção da totalidade das mercadorias e serviços produzida pela cletiv:dade em regime de ocupação plena, procurou-se atribuir ao Estado uma função compensatória dessa deficiência. Se o Estado é um consumidor de mercadorias e serviços e ao mesmo tempo responsável por um certo volume de investimentos, uma expansão das despesas correntes e de capital lo setor público pode determinar um aumento da procura global e, conseqüentemente, a ocupação de fatôres inativos. Simultâneamente, uma diminuição da pressão tributária sôbre o setor privado da economia, liberando rendimentos atribuídos aos fatôres, poderá determinar a expansão do consumo privado, maior procura de serviços e mercadorias e intensificação das atividades produtoras.

Uma política compensatória dêsse tipo conduzirá fatalmente ao deficit crçamentár:c, através da diminuição das receitas e ampliação das despesas públicas. O aumento das despesas correntes em consequêencia do alargamento dos serviços governamentais e o maior volume de investimentos públicos poriam em ação fatôres inativos e provocariam o restabelecimento do equilíbrio entre a oferta e a procura global de bens e serviços. O desequilíbrio orçamentário verificado estaria compensado pelo equilíbrio econômico restabelecirs. O deficit verificado tanto no orçamento corrente, quanto no de capitaı seria então coberto mediante aumento da dívida pública, empréstimos feitos ao Govêrno pelo sistema bancário e mesmo através de emissões de 
papel moeda de curso forçado, medidas essas destituídas de efeitos inflacionários quando existem fatôres de produção desocupados.

Em época de pleno emprêgo e de pressóes inflacionárias uma política fiscal compensatória age porém em sentido inteiramente inverso. Um deficit orçamentário em tais circunstâncias, resultante da expansão das despesas correntes e dos gastos de capital, não compensados por igual transferência de rendimentos e de poupança do setor privado, tem o efeito de aumentar a procura global de bens e serviços sem a correspondente ampliação da oferta, tornada esta impossível por já se encontrarem plenamente ocupados os fatôres de produção disponíveis. Em época de inflação, portanto, torna-se imperioso o rigoroso equilíbrio e mesmo a obtenção de superavit no orçamento de custeio e a limitação dos investimentos públicos ao total obtido através de empréstimos mais o saldo do orçamento corrente. Cumpre ainda notar que parte do orçamento de capital, em tais circunstâncias, deverá ser reservada para a amortização da dívida pública sensivelmente aumentada no período de depressão.

Esses princípios gerais aplicam-se, feitas as adaptações necessárias, a uma estrutura econômica atrasada em fase de desenvolvimento econômico. A política orçamentária em uma economia dêsse tipo, ao mesmo tempo que procura manter sob contrôle as pressões inflacionárias sempre intensas em uma fase de acentuada expansão, visa a acumulação da poupança requerida para o financiamento dos investimentos essenciais ao desenvolvimento. Tornase então imperioso o rigoroso equilíbrio do orcamento de custeio, com a limitação das despesas correntes e dos gastos de transferência, visando a acumu. lação de saldos orçamentários, poupança forçada provocada pelo Estado a fim de obter maior volume de recursos não inflacionários para financiar investimentos. Esses saldos somados ao produto dos empréstimos voluntários e compulsórios obtidos do público alimentarão o fundo capaz de financiar o programa de obras e empreendimentos ligados ao desenvolvimento econôm:co.

Uma excessiva expansão dos gastos correntes do Govêrno durante uma fase de desenvolvimento econômico tem os efeitos indesejáveis de aumentar as despesas de consumo e ampliar a procura global e que determinará o agravamento das pressões inflacionárias. A compressão das despesas de custeio da administração, ao mesmo tempo que restringe a procura de serviços e de bens de consumo, permite a poupança de maiores parcelas da renda nacional para mais rápida formação do capital necessário ao desenvolvimento do país. Da mesma forma, reduzindo-se os gastos de transferênçia, permite-se o acúmulo de maiores rendimentos em poder das classes e grupos de maior propensão para poupar e investir.

Em resumo, o deficit orçamentário não é uma categoria independente, nem o equilíbrio do orçamento público uma regra inflexível, válida em quaisquer circunstâncias. A política orçamentária, como aliás todos os instrumentos governamentais, deve ser usada como meio para se atingir o objetivo final do Estado, o bem comum ou a máxima vantagem social. Se em determinada conjuntura o desequilíbrio orçamentário serve melhor à consecução daquele objetivo e se torna possível, através dêle, aumentar o produto social, o ñível de emprêgo e o bem-estar geral, o deficit das contas públicas não só é justificável como aconselháve!. Mas, se em circunstâncias diferentes o 
deficıt orçamentärio é lín fator inflacionário, capaz de contribuir para o agravamento das condições de vida das classes menos favorecidas e de tornar mais agudas as desigualdades sociais, impõe-se o equilíbrio do orçamento püblico.

$\mathrm{Na}$ atual conjuntura brasileira, cabe inteira razão aos que advogam o equilíbrio dos orçamentos públicos, não só da União, como dos Estados e Municípios. Uma limitação dos gastos correntes com a manutenção e funcionamento dos serviços públicos e a sua cobertura integral por meio de receitas tributárias é uma condição essencial para o saneamento das finanças nacionais e contenção da inflação. A compressão das despesas de simples custeio da administração, dos gastos com a defesa nacional e das despesas militares, tornará possível a obtenção, no orçamento ordinário, de saldos correspondentes à contribuição do setor público para o aumento no volume da poupança global. Êsses saldos, adicionados ao produto dos empiéstimos obtidos vcluntária ou compulsòriamente do público, constituirão a receita destinada a financiar, sem agravamento das pressões inflacionárias, o programa de investimentos básicos tão essenciais ao desenvolvimento econômico do país e ao aumento do produto nacional.

Uma fase de expansão, característica do desenvolvimento econômico, contém uma tendência para o pleno emprêgo dos fatôres de produção disponiveis. Atingido o pleno emprêgo o aumento do produto nacional sòmente pode ser alcançado mediante consecução de maior produtividade dos fatôres existentes, processo lento e demorado. A oferta torna-se rígida e deverá enfrentar crescente aumento da procura global. Há portanto forte e continuada pressão para a alta de preços das mercadorias e serviços tornados cada vez mais escassos em conseqüência da predominância da procura sôbre a oferta. Um orçamento desequilibrado significa uma demanda de bens e serviços pelo Estado superior à parcela da renda nacional captada pelo Tesourn através da tributação ou de empréstimos obtidos do público. Agrava portanto o Estado o desequilíbrio já existente entre a oferta e a procura, ampliando esta última e provocando, dessa forma, maior elevação do nível geral dos preços.

É um êrro em perspectiva considerar a emissão de papel moeda de curso forçado como a causa determinante da elevação dos preços. O aumento dos meios de pagamento para a cobertura de deficit orçamentário é conseqüência de uma ampliação excessiva da despesa pública, ou seja da procura de bens e serviços pelo Estado, não balanceada por correspondente disponibilidade de renda transferida do setor privado para o setor público. Impossível será estancar a emissão se o equilíbrio orçamentário não fôr atingido. Para conseguir êsse objetivo ou reduz o Estado a despesa pública, isto é, a procura de bens e serviços pelo Govêrno, ou consegue, através da tributação e do empréstimo, transferir maior volume de renda do setor privado para o setor público.

Uma redução da despesa pública para a consecução do equilíbrio orçamentário significa menor participação do Estado no processo do desenvolvimento econômico e maior responsabilidade da iniciativa privada na realização dêsse processo. Manutenção de um alto nível de gastos públicos e consecução do equilíbrio orçamentário através de forte pressão tributária e aumento da 
dívida pública significam que o Estado prefere assumir o comando do processo de desenvolvimento econômico e chamar a si a responsabilidade principal da execução dos empreendimentcs e iniciativas ligados a êsse processo.

Em conclusão, o equilíbrio dos orçamentos públicos é condição necessária para que o desenvolvimento econômico se processe sem agravamento das pressões inflacionárias e dentro de um quadro de preços estáveis e de valor constante da moeda. Quanto à magnitude do orçamento, ou seja o total das despesas e das receitas públicas, está ela na estreita dependência das diretrizes da política econômica adotada e do papel atribuído ao Estado na realização do processo de desenvolvimento. Se à iniciativa e aos empreendimentos privados se reconhece papel predominante, o orçamento público será mantido dentro de totais limitados, usando o Estado de preferência os instrumentos da política monetária e de crédito para disciplinar a expansão do setor privado dentro da orientação considerada mais aconselhável. Se é porém considerada indispensável para aceleração do processo de desenvolvimento uma ação predominante e mais intensa do Estado bem como a execução pelo Govêrno dos grándes empreendimentos de base, ter-se-á que aceitar um volúme crescente de gastos públicos acompanhado de permanente agravação da pressão tributária e de volume crescente de empréstimos públicos.

A responsabilidade principal da inflação crônica que atormenta a ma:oria dos países subdesenvolvidos é a convicção errônea de ser possíve! expandir, simultânea e ilimitadamente, tanto as atividades do setor público quanto as atividades do setor privado. O crescimento dos orçamentos públicos não é acompanhado de contenção correspondente do setor privado através de agravação da pressão tributária e, freqüentemente, a ampliação das atividades privadas é mesmo incentivada por meio de uma política de crédit bancário fácil. Simultâneamente, uma política de elevação do nível de salarios e d€ redistribuição de rendimentos estimula a procura de bens de consumo e de serviços. O resultado é o aumento da procura de bens e serviços em ambos os setores da economia a qual, não podendo ser satisfeita por uma oferta inelástica ou de aumento lento e demorado, provoca a alta incessante do nível dos preços e do custo de vida, contra a qual se mostram impotentes os tabelamentos oficiais e os órgãos governamentais de contrôle.

O desenvolvimento equilibrado, sem instabilidade monetária e oscilações permanentes dos preços, da economia bnasileira, sòmente pode ser atingido dentro do quadro do erçamentos públicos equilibrados e de uma clara definição das tarefas e responsabilidades da iniciativa privada e do Govêrno na promoção dêsse desenvolvimento. 